\title{
Article \\ Copy Neutral LOH Affecting the Entire Chromosome 6 Is a Frequent Mechanism of $H L A$ Class I Alterations in Cancer
}

\author{
Maria Antonia Garrido ${ }^{1,+}{ }^{\text {, Francisco Perea }}{ }^{2,3,+}{ }^{\mathbb{C}}$, Jose Ramon Vilchez ${ }^{2}$, Teresa Rodríguez ${ }^{2,3}$, Per Anderson ${ }^{2,3}$, \\ Federico Garrido 2,3,4, Francisco Ruiz-Cabello 2,3,4,*(D) and Natalia Aptsiauri 3,4,*(D) \\ 1 Servicio de Radiología, UGC de Radiología, Hospital Virgen de la Nieves, 18014 Granada, Spain; \\ mariaa.garrido.collado.sspa@juntadeandalucia.es \\ 2 Servicio de Análisis Clínicos e Inmunología, UGC de Laboratorio Clínico, Hospital Universitario Virgen de \\ las Nieves, 18014 Granada, Spain; franciscoj.perea.garcia@juntadeandalucia.es (F.P.); \\ joser.vilchez.sspa@juntadeandalucia.es (J.R.V.); teresa.rodriguez.ruiz.sspa@juntadeandalucia.es (T.R.); \\ per.anderson@ibsgranada.es (P.A.); federico.garrido.sspa@juntadeandalucia.es (F.G.) \\ 3 Instituto de Investigación Biosanitaria IBS.GRANADA, 18014 Granada, Spain \\ 4 Departamento de Bioquímica, Biología Molecular III e Inmunología, Facultad de Medicina, \\ Universidad de Granada, 18071 Granada, Spain \\ * Correspondence: fruizc@ugr.es (F.R.-C.); naptsiauri@ugr.es (N.A.) \\ + These authors have contributed equally to the work.
}

\section{check for} updates

Citation: Garrido, M.A.; Perea, F.; Vilchez, J.R.; Rodríguez, T.; Anderson, P.; Garrido, F.; Ruiz-Cabello, F.; Aptsiauri, N. Copy Neutral LOH Affecting the Entire Chromosome 6 Is a Frequent Mechanism of HLA Class I Alterations in Cancer. Cancers 2021, 13, 5046. https://doi.org/10.3390/ cancers 13205046

Academic Editors: Ana María Zubiaga and Jone Mitxelena

Received: 28 July 2021

Accepted: 7 October 2021

Published: 9 October 2021

Publisher's Note: MDPI stays neutral with regard to jurisdictional claims in published maps and institutional affiliations.

Copyright: (C) 2021 by the authors Licensee MDPI, Basel, Switzerland. This article is an open access article distributed under the terms and conditions of the Creative Commons Attribution (CC BY) license (https:// creativecommons.org/licenses/by/ $4.0 /)$.
Simple Summary: Loss of antigen presentation due to the altered expression of tumor HLA class I (HLA-I) molecules is a common mechanism of cancer immune escape. Loss of HLA-I haplotype, locus or a single allele due to genetic and chromosomal aberrations, may result in reduced antigen presentation and, thus, facilitate immune evasion. Here, we demonstrate the prevalence of the copy neutral loss of heterozygosity $(\mathrm{CN}-\mathrm{LOH})$ involving $H L A-I$ heavy chain and B2M gene in various human tumor cell lines and tissues. We discuss the impact of the LOH in HLA genes on tumor immune rejection, clonal expansion and association with the cancer recurrence in the immunotherapy settings. It represents a genetic barrier for effective treatment and can be considered as a potential genetic biomarker of cancer immune escape.

Abstract: Total or partial loss of HLA class I antigens reduce the recognition of specific tumor peptides by cytotoxic $\mathrm{T}$ lymphocytes favoring cancer immune escape during natural tumor evolution. These alterations can be caused by genomic defects, such as loss of heterozygosity at chromosomes 6 and 15 (LOH-6 and LOH-15), where HLA class I genes are located. There is growing evidence indicating that $\mathrm{LOH}$ in HLA contributes to the immune selection of HLA loss variants and influences the resistance to immunotherapy. Nevertheless, the incidence and the mechanism of this chromosomal aberration involving HLA genes has not been systematically assessed in different types of tumors and often remains underestimated. Here, we used SNP arrays to investigate the incidence and patterns of LOH-6 and LOH-15 in a number of human cancer cell lines and tissues of different histological types. We observed that $\mathrm{LOH}$ in HLA is a common event in cancer samples with a prevalence of a copy neutral type of $\mathrm{LOH}(\mathrm{CN}-\mathrm{LOH})$ that affects entire chromosome 6 or 15 and involves chromosomal duplications. LOH-6 was observed more often and was associated with homozygous HLA genotype and partial HLA loss of expression. We also discuss the immunologic and clinical implications of $\mathrm{LOH}$ in HLA on tumor clonal expansion and association with the cancer recurrence after treatment.

Keywords: cancer immune escape; HLA class I; copy-neutral loss of heterozygosity (CN-LOH); antigen presentation; beta2-microglobulin; cytotoxic T-cells; cancer immunotherapy

\section{Introduction}

Tumor cells grow and metastasize despite an active cellular immune response mediated by $\mathrm{T}$ lymphocytes that recognize tumor antigens as peptides presented by human 
leucocyte antigens class I molecules (HLA-I). HLA is a complex genetic system encoding three heavy chain proteins (HLA-A, HLA-B and HLA-C) that are associated at the cell surface with a light chain, i.e., the $\beta 2$-microglobulin. HLA-I molecules present different antigenic peptides to T-cells and stimulate cellular immune responses. It is well known that loss of tumor HLA-I expression is a common mechanism of cancer immune escape from cytotoxic T-lymphocytes (CTL) [1]. There are multiple molecular mechanisms causing altered $H L A-I$ expression in tumors, including mutations of $H L A-I$ heavy chain and $\beta 2$-microglobulin (B2M) genes [2,3], transcriptional downregulation [4], selective $H L A$ allelic losses [5], hypermethylation [6] and loss of heterozygosity (LOH) involving HLA genes (LOH HLA) at chromosome 6 that causes HLA haplotype loss [7-10]. Frequently, the loss of one copy of the B2M gene due to $\mathrm{LOH}$ at chromosome 15 ( $\mathrm{LOH} \mathrm{B2M}$ ), together with a mutation in the second allele, results in a complete loss of HLA-I expression [11-13]. All these mechanisms can be classified into regulatory ("soft"), which can be reversed by cytokines and structural ("hard") defects producing irreversible HLA alterations [14]. Some alterations have higher incidence in certain types of malignancy. For instance, mutations in the B2M gene are typical for melanoma and MSI-H colorectal carcinoma [15], while a transcriptional downregulation of $H L A-I$ can be frequently detected in bladder cancer [4]. $\mathrm{LOH}$ involving HLA-I genes is a frequent "hard" mechanism responsible for HLA haplotype loss that reduces the repertoire of tumor antigens presented to T-cells $[13,16]$. In normal conditions, all six HLA-I genes are expressed on each nucleated human cell. However, $\mathrm{LOH}$ can cause a simultaneous loss of all three HLA-I genes leading to a loss of HLA haplotype, or selective locus and allelic absences. It is known that each HLA allele can present a distinct range of tumor neoantigens to CTL. Thus, even a partial loss of HLA-I can impair specific antigen presentation and T-cell mediated tumor rejection. In a recent publication, loss of a single HLA locus or allele was shown to have an impact on the overall survival in cancer [17].

There is accumulating evidence that tumor HLA-I loss or altered expression reduces the efficacy of cancer immunotherapy and the mechanism is associated with the reduced T-cell cytotoxicity. More recently, LOH involving HLA genes has been linked to increased resistance to immunotherapy and cancer recurrence [18-21]. A subset of patients harboring LOH-6 in had poorer survival after treatment with checkpoint blockade therapy [22].

In general, $\mathrm{LOH}$ is a common form of allelic imbalance in cancer and the detection of LOH has been used to identify genomic regions that harbor tumor suppressor genes and to characterize different tumor types, pathological stages and progression. $\mathrm{LOH}$ can be caused by total chromosomal loss due to mitotic nondisjunction or by chromosomal deletions due to errors during mitotic recombination and a defective DNA damage response [23,24]. $\mathrm{LOH}$ of critical chromosomal regions in many cancers suggests a selection of $\mathrm{LOH}$ events that increase the survival of tumor cells during cancer initiation and progression, such as inactivation of tumor suppressor genes and immune genes [25]. Moreover, $\mathrm{LOH}$ could also be observed in premalignant cells and at early stages of neoplastic transformation.

Therefore, it is important to characterize the pattern and extension of LOH-6 and -15, because $\mathrm{LOH}$ can cause a loss of the entire chromosomes, or only some parts that may or not include the HLA and B2M genes. In addition, there are chromosomal duplications observed during cancer progression that result in a copy number neutral $\mathrm{LOH}(\mathrm{CN}-\mathrm{LOH})$, an alteration difficult to detect, which might potentially influence the ability of tumor cells to evade the antitumor immunity. We have previously reported in melanoma cell lines that the percentage of $H L A$ homozygosity is much higher than in normal healthy donors [26]. In this case, a homozygous HLA genotype could suggest LOH at the HLA genetic region. Hence, it is important to develop techniques to detect $\mathrm{LOH}$ in the HLA and B2M genomic regions in DNA obtained from solid tumor tissues as well as in tumor cell lines.

In this study, using SNP arrays, we investigated the prevalence of $\mathrm{LOH}$ at chromosomes 6 and 15 in a number of human cancer cell lines of different histological type and discuss the potential immunologic and clinical implications of these chromosomal aberrations in tumor evolution. 


\section{Materials and Methods}

\subsection{Human Tumor Cell Lines and Tumors}

We analyzed a total of 31 human tumor cell lines of distinct histological types (Table 1). Most of them, including 4 breast, 4 lung, 6 bladder cell lines and 4 myelodysplastic syndrome (MDS) blasts were randomly included into the study without previous knowledge of the HLA genotype. Bladder, breast and lung cancer cell lines were purchased from the American Type Culture Collection (ATCC). In addition, 13 melanoma cell lines were selected out of 91 in total (14\%) based on a homozygous HLA genotype and positive total HLA-I cell surface expression [27]. 11 of them were from the European Searchable Tumor Cell Line Data Base (ESTDAB, http:/ / www.ebi.ac.uk/ipd/estdab / , accessed on 5 November 2020 [26,27]. One melanoma cell line with total loss of HLA-I due to a B2M mutation (M010) was kindly provided by Dr. Gaudernak/Dr. Kyte (University of Oslo, Oslo, Norway) [13] and another melanoma cell line Ando-2 (with a loss of HLA haplotype) was kindly provided by Dr. Coulie (Université de Louvain (UCL), Brussels, Belgium). Malignant CD34+ blast cells were obtained from 27 patients with MDS from the Hospital Virgen de las Nieves in Granada, Spain [28]. Four of these patients showed LOH and these cases are included in Table 1.

Cell lines were cultured in Dulbecco's Modified Eagle Medium (Sigma-Aldrich, St. Louis, MO, USA) or RPMI1640 supplemented with 10\% FBS (GIBCO, Thermo Fisher Scientific, Waltham, MA, USA ), 2 mmol/L glutamine (Sigma-Aldrich, St. Louis, MO, USA) and $100 \mathrm{U} / \mathrm{mL}$ penicillin/streptomycin (GIBCO, Thermo Fisher Scientific, Waltham, MA, USA) at $37^{\circ} \mathrm{C}$ in a $5 \%$ of $\mathrm{CO}_{2}$ atmosphere.

In addition, we analyzed four bladder tumor tissue samples and autologous peripheral blood mononuclear cells (PBMCs) provided by the regional Biobank. Informed consent approved by the Ethics Committee of our institution was signed by all the patients included in this study. Previously, all medical records and tumor sections were reviewed by both urologist and pathologist. The tumor histological subtype in all cases was urothelial. These samples previously were studied by immunohistochemistry and showed positive $H L A-I / \beta 2 M$ complex immunolabeling with selective HLA losses.

\subsection{Bladder Tumor Tissue Immunohistochemistry and Microdissection}

After transurethral tumor resection bladder tumor tissue samples were immediately stored at $-80^{\circ} \mathrm{C}$. Cryosections were obtained using a microtome-cryostat (Bright), allowed to dry at room temperature for $4-18 \mathrm{~h}$, fixed in acetone at $4{ }^{\circ} \mathrm{C}$ for $10 \mathrm{~min}$ and stored at $-80{ }^{\circ} \mathrm{C}$ until further analysis. Immunolabeling was performed using Biotin-Streptavidin kit (supersensitive Multilink HRP/DAB kit, BioGenex, The Hague, The Netherlands). Tissue sections were evaluated by two independent pathologists.

We analyzed the following molecules using specific monoclonal antibodies: W6/32against $H L A-A,-B$ and $-C$ heavy chain / $\beta 2 M$ complex (a gift from Dr. Bodmer, Imperial Cancer Research Fund Laboratories, London, UK); GRH-1, which recognizes free and heavy chain-associated $\beta 2 M$ (produced and characterized in our laboratory); HC-10 against free $H L A-B$ and $-C$ heavy chains (Nordic-MUbio, Rangeerweg, The Netherlands), anti-HLA- $A$ which recognizes a subset of $H L A-A$ locus [29] and 42IB5 against the HLA-B locus [30].

For the LOH analysis we selected four tumor samples with positive $H L A-A B C / \beta 2 M$ immunolabeling and selective loss of an HLA locus. Cryopreserved tissue sections $(8-10 \mu \mathrm{m}$ thick) from these four tumors were fixed in $70 \%$ ethanol, stained with a $0.05 \% w / v$ solution of toluidine blue and microdissected using a laser micromanipulator (PALM MicroLaser Systems, ZEISS Göttingen, Germany). The obtained fragments were collected in PALM Adhesive Caps and DNA was isolated from them using QIAamp Tissue Kit (QIAGEN, Hilden, Germany). In all cases, normal autologous DNA was obtained from PBMCs. 
Table 1. Analysis of the LOH in chromosomes 6 and 15 in human tumor cell lines and bladder tumors.

\begin{tabular}{|c|c|c|c|c|c|c|c|}
\hline Histological Type & Sample & SNP-A Chr6-Range & Size $(\mathbf{M b})$ & $\begin{array}{l}\text { LOH of the } \\
\text { HLA Region }\end{array}$ & SNP-A Chr15-Range & Size $(\mathbf{M b})$ & $\begin{array}{l}\text { LOH of the } \\
B 2 M \text { Gene }\end{array}$ \\
\hline \multicolumn{8}{|c|}{ Melanoma (CCL) } \\
\hline & E037 & CN-LOH 6pterqter & & YES & CN-LOH 15q11.2qter * & & YES \\
\hline & E040 & LOH6pterp12.1,6pterq24.3* & $55,148 *$ & YES & normal & & NO \\
\hline & E055 & $\begin{array}{l}\text { CN-LOH } \\
\text { 6ptergter*6q12qter }\end{array}$ & 104 & YES & normal & & $\mathrm{NO}$ \\
\hline & E058 & CN-LOH 6pterqter & & YES & CN-LOH 15q22.2qter * & $41.8^{*}$ & NO \\
\hline & E062 & CN-LOH 6ptergter & & YES & CN-LOH 15q11.2q23 * & $50 *$ & YES \\
\hline & E064 & CN-LOH 6ptergter* & & YES & normal & & NO \\
\hline & E070 & CN-LOH 6pterp21.3 & 33.4 & YES & normal & & NO \\
\hline & E071 & CN-LOH 6pterqter & & YES & normal & & NO \\
\hline & E081 & CN-LOH 6pterqter & & YES & normal & & NO \\
\hline & E019 & $\begin{array}{c}\text { CN-LOH } \\
\text { 6pterater*6q15.1qter }\end{array}$ & 177 & YES & CN-LOH 15q14q22.2 & 25 & YES \\
\hline & E124 & $\begin{array}{l}\text { opterqter }, \text { oq15.1qter } \\
\text { CN-LOH 6pterq12 }\end{array}$ & 65 & YES & CN-LOH 15q11.2qter * & & YES \\
\hline & $\begin{array}{l}\text { E124 } \\
\text { M010 }\end{array}$ & CN-LOH 6pterqter & 63 & $\begin{array}{l}\text { YES } \\
\text { YES }\end{array}$ & CN-LOH 15q11.2qter & & $\begin{array}{l}\text { YES } \\
\text { YES }\end{array}$ \\
\hline & Ando & CN-LOH 6pterqter & & YES & CN-LOH 15q11.2qter* & & YES \\
\hline \multicolumn{8}{|c|}{ Breast (CCL) } \\
\hline & $\begin{array}{l}\text { MDA- } \\
\text { MB4-435 }\end{array}$ & $\mathrm{CN}-\mathrm{LOH}$ 6pterqter & & YES & $\begin{array}{c}\text { CN-LOH } \\
15 \mathrm{q} 21.1 \mathrm{q} 21.3 * 15 \mathrm{q} 22.2 \mathrm{qter} *\end{array}$ & $10 *, 41 *$ & NO \\
\hline & IMIM- & CN-LOH 6pterqter & & YES & CN-LOH 15q11.2q21.2 & 30 & YES \\
\hline & MCF-7 & CN-LOH 6p21.31q25.2 * & $122 *$ & NO & CN LOH 15q11.2q23* & $50 *$ & YES \\
\hline & $\begin{array}{l}\text { MDA-MB- } \\
231\end{array}$ & Normal & & NO & No data & & No data \\
\hline \multicolumn{8}{|c|}{ Leukemia (CCL) } \\
\hline & X31364 & CN-LOH 6pterp21.31 & 34 & YES & normal & & $\mathrm{NO}$ \\
\hline & $\mathrm{X} 28751$ & CN-LOH 6pterp 12.3 & 47 & YES & normal & & NO \\
\hline & X29708 & CN-LOH 6pterp21.31 & 36 & YES & normal & & NO \\
\hline & X30279 & CN-LOH 6pterp21.2 & 38 & YES & normal & & NO \\
\hline \multicolumn{8}{|c|}{ Lung (CCL) } \\
\hline & SKMES & $\begin{array}{c}\text { CN-LOH } \\
\text { 6ptergter*6pterp12.2 }\end{array}$ & 52 & YES & CN-LOH 15q11.2qter * & & YES \\
\hline & SKLU-1 & CN-LOH 6pterqter & & YES & CN-LOH 15q11.2qter & & YES \\
\hline & CALU6 & CN-LOH 6 ptergter & & YES & CN-LOH 15q11.2qter* & & YES \\
\hline & A427 & CN-LOH 6pterqter & & YES & normal & & NO \\
\hline \multicolumn{8}{|c|}{ Bladder (CCL) } \\
\hline & $\begin{array}{c}\text { RT4 } \\
\text { (HTB-2) }\end{array}$ & CN-LOH 6q21q27 * & 49 & NO & CN-LOH 15q11.2qter * & & YES \\
\hline & $\begin{array}{l}5637 \\
\text { (HTB-9) }\end{array}$ & CN-LOH 6q16.3qter * & $66^{*}$ & NO & CN-LOH 15q11.2qter * & & YES \\
\hline & $\begin{array}{l}\text { TCCSUP } \\
\text { (HTB-5) }\end{array}$ & $\begin{array}{c}\text { CN-LOH } \\
\text { 6pterp22.3,6q12q25.2 }\end{array}$ & 22,87 & NO & CN-LOH 15q11.2qter* & & YES \\
\hline & WILL & CN-LOH 6pterqter & & YES & $\begin{array}{c}\text { CN-LOH } \\
15 q 11.2 \mathrm{q} 14^{*}, 15 \mathrm{q} 21.3 \mathrm{q} 26.2 *\end{array}$ & $16^{*}, 42 *$ & $\mathrm{NO}$ \\
\hline & $\begin{array}{c}\mathrm{J} 82 \\
(\mathrm{HTB}-1)\end{array}$ & $\mathrm{CN}-\mathrm{LOH} 6$ pterqter & & YES & normal & & NO \\
\hline & $\begin{array}{c}\text { T24 } \\
(\mathrm{HTB}-4)\end{array}$ & CN-LOH 6pterqter & & YES & CN-LOH 15q11.2qter * & & YES \\
\hline \multicolumn{8}{|c|}{ Bladder (TT) } \\
\hline & V039 & CN-LOH 6pterqter * & & YES & normal & & $\mathrm{NO}$ \\
\hline & V164 & CN-LOH 6pterp21.1 & 49.5 & YES & normal & & NO \\
\hline & V24 & CN-LOH 6pterp21.2 & 39 & YES & normal & & NO \\
\hline & V315 & CN-LOH 6q13qter & 95.1 & NO & CN-LOH 15q11.2qter & & YES \\
\hline
\end{tabular}

CCL: cancer cell lines, TT: tumor tissue, ${ }^{*}$ Heterogeneous or clonal CN-LOH, with only a percentage of affected cells.

\subsection{Analysis of HLA Genomic Copy Number Alterations by Single Nucleotide Polymorphism (SNP) Arrays}

DNA was isolated from the studied tumor cells and from microdissected bladder tumors and autologous PBMCs and was genotyped using the Illumina Infinium assay on the Immunochip according to manufacturer protocol. It detects about 200,000 SNPs selected based on GWAS of the diseases of the immune system. Loss of heterozygosity $(\mathrm{LOH})$ and copy number results were obtained using the Illumina Genome studio software as "theta" and "R" values. The SNP analysis in each type of cells or tumors has been done twice with $100 \%$ reproducibility. We used immunochip data from unrelated samples of European ancestry to obtain a median fluorescence value per probe to create such a standard and to subsequently obtain $\log \mathrm{R}$ ratios [10,28]. A $\log \mathrm{R}$ ratio distribution around zero can be regarded as copy neutral $(\mathrm{CN})$, while chromosomal intervals of mainly positive (or negative) log Ratios can be interpreted as a gain or a loss of chromosomal DNA. Figure 1 summarizes different patterns of $\mathrm{LOH}$ that can be obtained using SNP gene arrays. Upper plot shows the variants of B allele frequency (BAF), which indicates the zygosity 
of each SNP: a physiological situation that comprises equal representation of $\mathrm{AA}, \mathrm{AB}$ and $\mathrm{BB}$ genotypes, respectively, and displaying $\mathrm{B}$ allele frequencies of $0,0.5$ and 1 . Zero is frequency of allele A, 1 is the frequency of allele B and 0.5 corresponds to the heterozygous $A B$ version of the genome. When the BAF pattern has all three mentioned above values, the sample is heterozygous (AB) and there is no $\mathrm{LOH}$. When it lacks polymorphisms at 0.5 , the sample is homozygous and has $\mathrm{LOH}$.
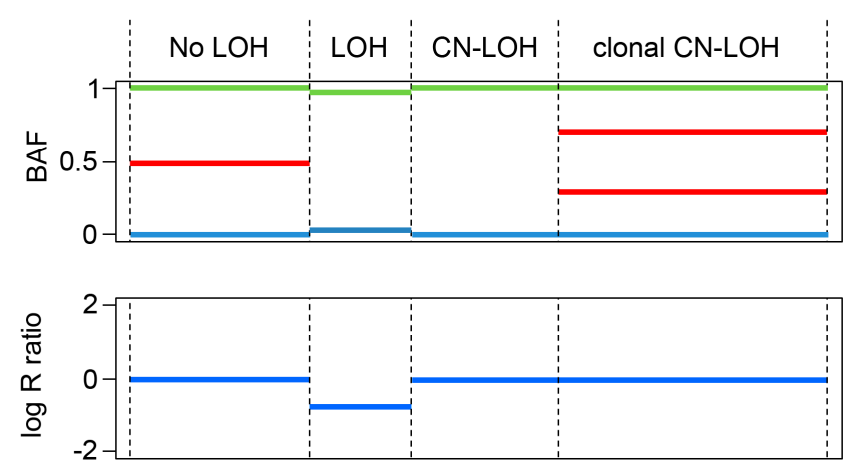

Figure 1. Schematic illustration of LOH assay using SNP arrays using the Illumina Infinium SNP Immunochip. The schematic genomic plots show patterns of B-allele frequency (BAF) (top panel) and corresponding $\log \mathrm{R}$ ratios (bottom panel) along the analyzed chromosome (x-axis) demonstrating cases of heterozygosity (no LOH), LOH due to loss of genetic material ( $\mathrm{LOH}$ ), copy number neutral $(\mathrm{CN}-\mathrm{LOH})$ and clonal CN-LOH (a mixture of cells with $\mathrm{CN}-\mathrm{LOH}$ and normal heterozygous cells).

The lower plot shows the $\log \mathrm{R}$ ratio, which is a measure of SNP CN variation, with a normal value defined as 0 , reflecting a copy number neutral loss of heterozygosity (CN-LOH).

Some samples can have clonal LOH, or have a heterogeneous composition, representing a mixture of tumor cells with $\mathrm{CN}-\mathrm{LOH}$ and without $\mathrm{LOH}$. Some of these cells reflect clonal tumor evolution with heterogeneous $\mathrm{CN}-\mathrm{LOH}$. In that case, the heterogeneous $\mathrm{AB}$ pattern has an additional line at BAF and the distance between these two lines (red lines on Figure 1) will reflect the approximate percentage of cells with $\mathrm{CN}-\mathrm{LOH}$ in the tumor cell mixture. We used the University of California in Santa Cruz (UCSC, Santa Cruz, CA, USA) Genome Browser (http:/ / genome.ucsc.edu/, accessed on 6 March 2021) to map and characterize the range of the missing regions in chromosomes 6 and 15 (GRCh38/hg38 Assembly).

\section{Results}

\section{Analysis of LOH-6 and LOH-15 in Human Cancer Cell Lines}

We demonstrate $\mathrm{CN}-\mathrm{LOH}$ at chromosomes 6 and 15 in a variety of human tumor cell lines, in leukemia blasts and in human bladder tumors using SNP genomic analysis.

Breast, lung and bladder cancer cell lines were selected randomly from the ATCC. Melanoma cell lines and bladder tumor tissue samples were selected based on the loss of $H L A$ haplotype (homozygous HLA genotype) with apparently positive $H L A-A B C / \beta 2 M$ expression detected by flow cytometry or immunohistochemistry with some selective locus or allelic loss [27]. Figure 2 depicts an example of a bladder tumor with a selective HLA- $A$ locus loss. In the ESTDAB melanoma collection, around 14\% (13/91) of the cell lines are homozygous for $H L A-I[26,27]$. We have previously observed an increased incidence of HLA-I homozygosity as compared to the control group (922 samples from the Spanish Bone Marrow Donor Registry) in which the frequency of homozygosity for HLA-I and -II genes is around $1.3 \%$ [28]. We detected CN-LOH involving the HLA region, with different deletions and complex patterns of chromosomal loss in all four leukemia blasts and in many cells lines: in two out of four breast cancer cell lines, in all four lung cancer cell lines and in three out of six bladder cancer cell lines (Table 1). Later we checked the HLA genotype of these cell lines and discovered that those with LOH HLA were homozygous, 
which confirms that $\mathrm{LOH}$ is a mechanism of HLA haplotype loss in these samples. Using SPN array assay we were able to see the extent of chromosomal alterations. Figure 3 demonstrates representative examples of observed $\mathrm{LOH}$ patterns in the studied tumor cell lines and tumors. Notably, 13 melanoma cell lines selected (out total of 91) for this study demonstrated different patterns of B-allelic Frequency indicating $\mathrm{CN}-\mathrm{LOH}$ at chromosome $6(14 \%)$ (Table 1). Among them, 7 cell lines with total loss of entire chromosome 6 (CN$\mathrm{LOH}$ range-6pterqter) (Figure 3) showed a chromosome duplication and $\mathrm{CN}-\mathrm{LOH}$ in chromosome 6 involving the region of the HLA-A, HLA-B and HLA-C genes (CN-LOH $H L A)$.

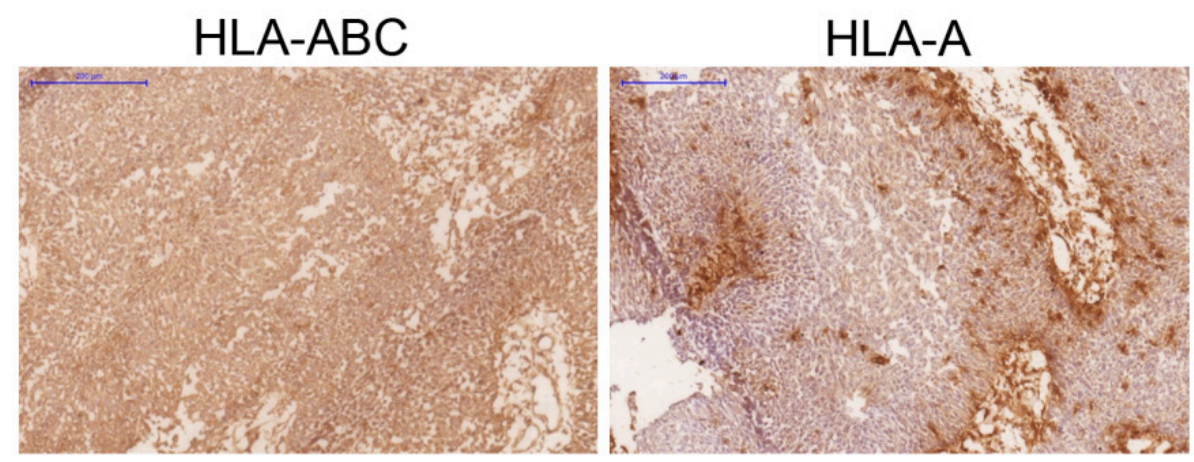

Figure 2. Immunohistological analysis of $H L A$ class I expression in a bladder tumor tissue demonstrating a positive expression of total $H L A-A B C / \beta 2 M$ complex and a selective loss of $H L A-A$ locus. Blue scale bar: $200 \mu \mathrm{m}$.

We observed these patterns of CN-LOH in the majority of the studied cell lines, including the breast cancer cell lines MDA-MB4-435S and IMIM-MA2. On the contrary, MCF7 cells showed clonal CN-LOH in the region which does not include HLA genes (Table 1). SNP analysis of chromosome 15 showed different variations of LOH-15 in three breast cancer cell lines, CN-LOH in all IMIM-MA2 cells and clonal CN-LOH in MDA-MB4$435 \mathrm{~S}$ and MCF7 cells. Notably, IMIM-MA2 showed CN-LOH involving both HLA genes and B2M (Figure 3). Overall, LOH-6 was more frequent than LOH-15 and without any correlation between these two alterations.

Three out of six studied bladder cancer cell lines (selected randomly from ATCC) showed CN-LOH of the entire chromosome 6 (Table 1). The cell lines HTB2, 5637 and HTB5, presented CN-LOH only in 6q region without any alterations in HLA-I region. Almost all bladder cell lines also demonstrated $\mathrm{CN}-\mathrm{LOH}$ at chromosome 15 and in four cell lines it involved the B2M gene region (Table 1). Importantly, all bladder cancer cell lines showed positive cell surface $H L A-I$ / $\beta 2 M$ expression as measured by FACs using a wide panel of antibodies against different $H L A$ specificities. In some cases, there was a downregulation of HLA-I locus or allele, in most of the cases inducible by IFN- $\gamma$.

All four studied bladder tumors had $\mathrm{CN}-\mathrm{LOH}$ at chromosome 6, in three of which this aberration involved $H L A-A B C$ genes. In one of these three tumors, $\mathrm{LOH}-6$ affected the entire chromosome 6 (6pterqter) (V039), but only in a proportion of cells (clonal CN-LOH-6 (Table 1, Figure 3). Tumor sample V24 also showed clonal CN-LOH in 6p region where HLA gene are located, but without a deletion of the entire chromosome (Table 1). Interestingly, three tumors with LOH-6 had no LOH-15 and the only LOH-6-free tumor V315 showed $\mathrm{CN}-\mathrm{LOH}-15$ involving entire chromosome 15 including the $B 2 M$ gene.

Overall, a total loss of chromosome 6 (6pterqter) we found in 17 analyzed samples $(97 \%)$, in two of which only a proportion of cells were affected by this alteration (clonal $\mathrm{CN}-\mathrm{LOH}$ ). Analysis of the region of chromosome 15 where the $B 2 \mathrm{M}$ gene is located, overall, demonstrated lower percentage of CN-LOH (54\% or 19/31), of which in 15 cases it involved the B2M gene. Among these 15 samples, 12 showed a total loss of chromosome 15 (15q11.2qter) in all cells and in 10 cases this loss was detected only in a proportion of the cells (clonal LOH-15) (Table 1, Figure 3). In three samples, LOH-15 did not affect the B2M gene. Some examples of these patters can be seen in Figure 3. Thus, the total loss of 
chromosome 15 (15q11.2qter) was less frequent than the total LOH-6 (6pterqter) and it was mostly with a subclonal pattern. Notably, none of the CD34+ blasts from four patients with MDS showed LOH-15 (Table 1) and only one bladder tumor was with CN-LOH-15.

\section{Chromosome 6 (HLA)}

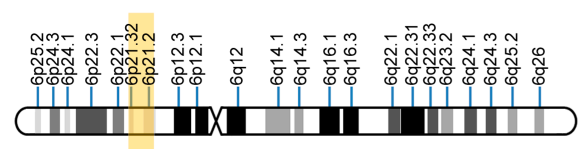

\section{Chromosome 15 (B2M)}

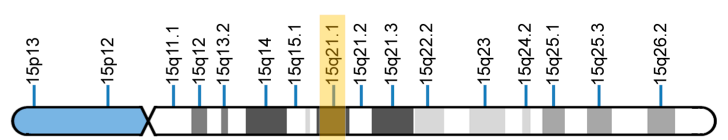

A No LOH
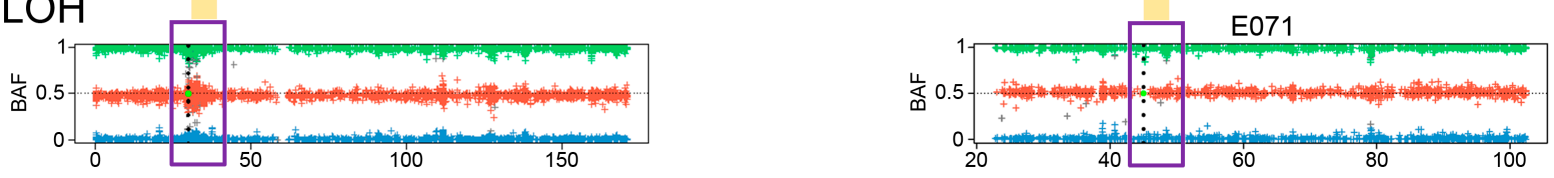

B Complete CN-LOH of Chr6 and Chr15
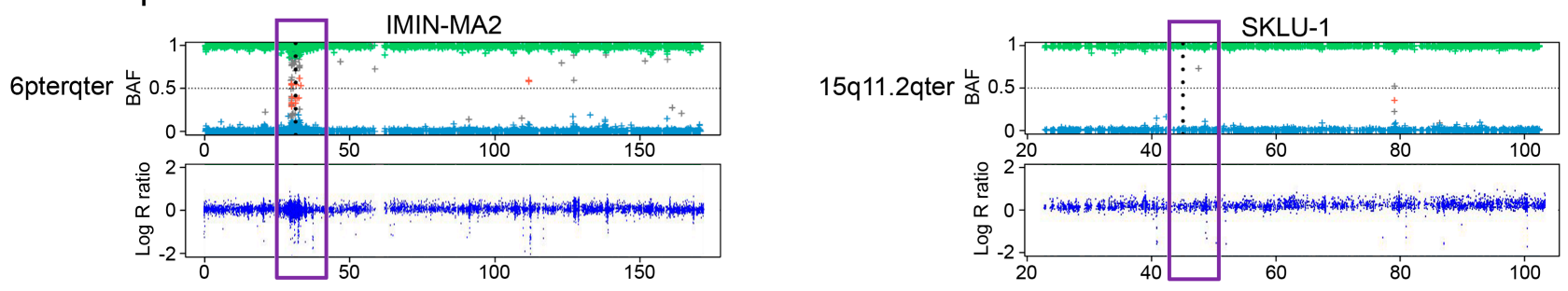

\section{Partial $\mathrm{CN}-\mathrm{LOH}$ involving the HLA region and $B 2 M$}

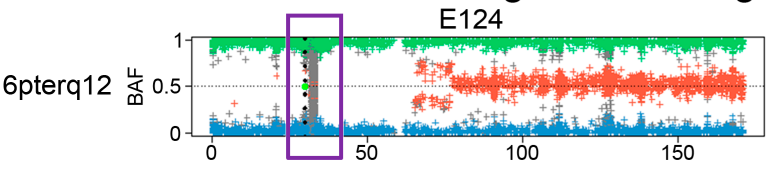

$15 q 11.2 q 21.2$ 崖

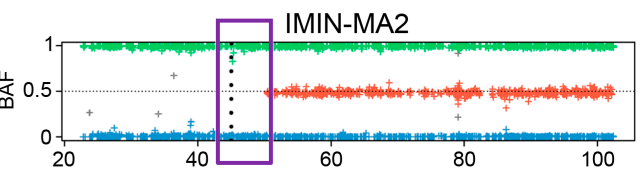

\section{Clonal CN-LOH of Chr6 and Chr15 (Complete CN-LOH in a fraction of the cells)}
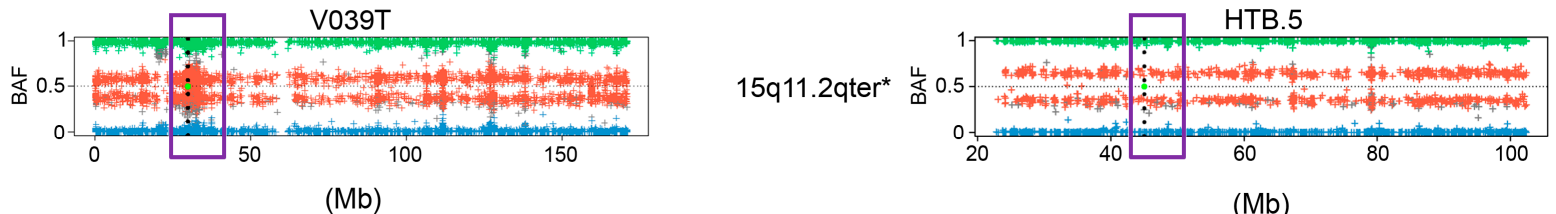

$(\mathrm{Mb})$

Figure 3. Examples of different CN-LOH patterns at chromosomes 6 (left panel) and 15 (right panel), involving HLA and $B 2 M$ genomic regions, respectively, in human tumor cell lines and in microdissected bladder tumors. (A) Examples of cell lines without $\mathrm{LOH}$; (B) Cell lines with a complete loss of a chromosome 6 and 15 (CN-LOH); (C) Partial CN-LOH involving HLA and B2M genes; (D) Complete CN-LOH in a fraction of cells, clonal CN-LOH $\left(^{*}\right)$.

In summary, the most relevant finding in our study is that $\mathrm{LOH}$ is a common chromosomal alteration in tumor cells and tissues. All the samples evaluated in this study (except for one) showed $\mathrm{CN}-\mathrm{LOH}$ at chromosome 6 and more than half of the samples demonstrated CN-LOH at chromosome 15. Importantly, the most frequently observed pattern was CN-LOH-6 involving the whole chromosome 6 (6pterqter) (Table 1, Figure 3).

\section{Discussion}

$H L A-I$ is a highly polymorphic set of genes with each allele capable of presenting a specific and limited set of antigens to T cells. Humans are normally heterozygous at the $H L A-A,-B$ and $-C$ loci, which maximizes the variety of peptide that can be presented, improving responses to pathogens and tumors alike [31,32]. Hence, LOH-6 at HLA locus reduces the capacity of neoantigen presentation, thereby helping immune evasion of tumors. 
Importantly, even the loss of one HLA locus or allele can have an impact on the overall survival in cancer [17]. LOH-6 involving HLA genetic region is frequently found (20-40\%) in a variety of tumors suggesting is a widespread mechanism occurring independently of the origin of the tumor, i.e., tissue or etiology [16]. In this study, we found LOH-6 in about $97 \%$ of the analyzed samples, most of them copy neutral (CN-LOH), involving the entire chromosome and causing HLA haplotype loss. The frequency of LOH-15 was lower (54\%) and also mostly copy neutral (CN-LOH).

LOH causing HLA alterations might potentially influence the ability of tumor cells to evade the antitumor immunity, promote cancer progression and reduce patient survival [33]. In adult glioblastoma patients, LOH of HLA-I was associated with shorter overall survival [34]. In cervical carcinoma, LOH on 6p21.2 was found to be an important predictor of recurrence after radiation treatment, both overall survival and relapse-free survival were significantly worse for the patients with LOH as compared with those without LOH [35]. Previously, some groups have correlated loss of HLA-I with tumor grade/stage [36]. On the other hand, our group described LOH-6 in different types of cancer and did not see any link with tumor stage or differentiation grade [5]. In a more recent study of NSCLC, we did not find a direct association between tumor stage/grade and HLA-I or PD-L1 expression analyzed separately [10].

LOH-15 in B2M genetic area also is a frequent alteration in malignant cells [16]. It is enriched in different types of cancer, including breast, bladder and MSS colon carcinomas and it might be the initial event toward complete loss of the $B 2 M$ gene. We have previously reported that $\mathrm{LOH}$ affecting HLA genes is an early event during carcinogenesis that is later followed by other genomic alterations such as $B 2 M$ point mutations [13]. We were able to observe an immune escape of tumor cells harboring a specific $B 2 M$ mutation in a primary tumor to a totally HLA-I negative tumor cells in a distant metastasis with the same mutation and $\mathrm{LOH}$ at chromosomes 15 and 6. Another study by Chen et al., also suggest that LOH in HLA occurs early on in tumorigenesis [37].

In this study, some samples showed a subclonal pattern of $\mathrm{LOH}$, indicating the presence of a heterogeneous population of tumor cells within the sample, with and without $\mathrm{LOH}$. Recent publications demonstrate a clonal evolution of tumors with LOH-6, involving the HLA genes, suggesting that this alteration is an early event in carcinogenesis and combined with other alterations, such as mutations in $\beta 2 M$ or other genes involved in antigen presentation, could drive tumor evolution towards a more advanced stage. Importantly, there is strong evidence indicating that these $H L A$ alterations accumulate as a result of a strong selective pressure from the tumor immune microenvironment leading to cancer immune escape and to resistance to immunotherapy. In Figure 4 we illustrate this hypothetical progressive accumulation of $\mathrm{LOH}$ and mutations in HLA genes during natural cancer evolution. Therefore, $\mathrm{LOH}$ involving the HLA genetic region can occur at very early stages of carcinogenesis, when tumor cells are still HLA-I positive.

Thus, while a strong anti-tumoral immune response is pivotal for the eradication of malignant cells, it can also promote escape variants by directly enhancing genomic instability (mutations/LOH in HLA and APM genes).

Understanding the primary and secondary immune evasion and discovering biomarkers that can predict the response to immunotherapies are of key importance. It seems that HLA-I homozygosity and LOH at HLA-I represent a genetic barrier to effective immunotherapy. Chowell et al., analyzed $H L A-I$ genotype ( $H L A-A,-B$ and $-C$ ) in solid tumors from a cohort of cancer patients (NSCLC and melanoma) treated with anti-CTLA-4 or anti-PD-1 therapy and discovered that maximal heterozygosity at HLA-I loci improved overall survival after ICB compared with patients who were homozygous for at least one HLA locus [17].

Apart from being a predictive marker for the success of immunotherapy, LOH in HLA could result in secondary immune evasion which has been described in several cancers, including bladder, melanoma and lung cancer [38]. Studies by our laboratory showed that Bacillus Calmette-Guerin immunotherapy of bladder cancer induced the selection of 
HLA-I-deficient tumor cells with LOH in chromosome 6 and 15 [18]. Alterations in the $H L A-I$ antigen presenting pathway were also detected in recurrent metastatic melanoma following C-Vax/BCG vaccine immunotherapy [39]. In a melanoma patient, resistance to peptide-based immunotherapy was linked to inactivation of $\beta 2 M$ caused by a mutation and $\mathrm{LOH}$ at chromosome 15 [40]. Similarly, melanoma patients, receiving anti-PD-1 therapy (pembrolizumab), developed immune escape lesions with $\mathrm{LOH}$ in JAK2 and a truncating mutation in B2M [19]. Sade-Feldman and colleagues analyzed escape lesions from five melanoma patients treated with Ipilimumab (anti-CTLA4 Abs) and found LOH in B2M in $29.4 \%$ of the cases [21]. Another example of acquire resistance to ICIs was described by Gettinger et al. who demonstrated a complete genomic loss of B2M (a copy number variation) in lung cancer lesions after anti-PD-L1 and anti-CTLA-4 treatment [20]. In addition, it has been reported that $\mathrm{LOH}$ on $6 \mathrm{p} 21.2$ correlates with the recurrence of cervical carcinoma after radiotherapy [35]. Therefore, detection and monitoring the evolution of tumor HLA-I expression defects before and during the course of treatment is also important to guide a selection of optimal immunotherapy.

\section{LOH IN HLA-I AND $\beta 2 m$ DURING TUMOR DEVELOPMENT}

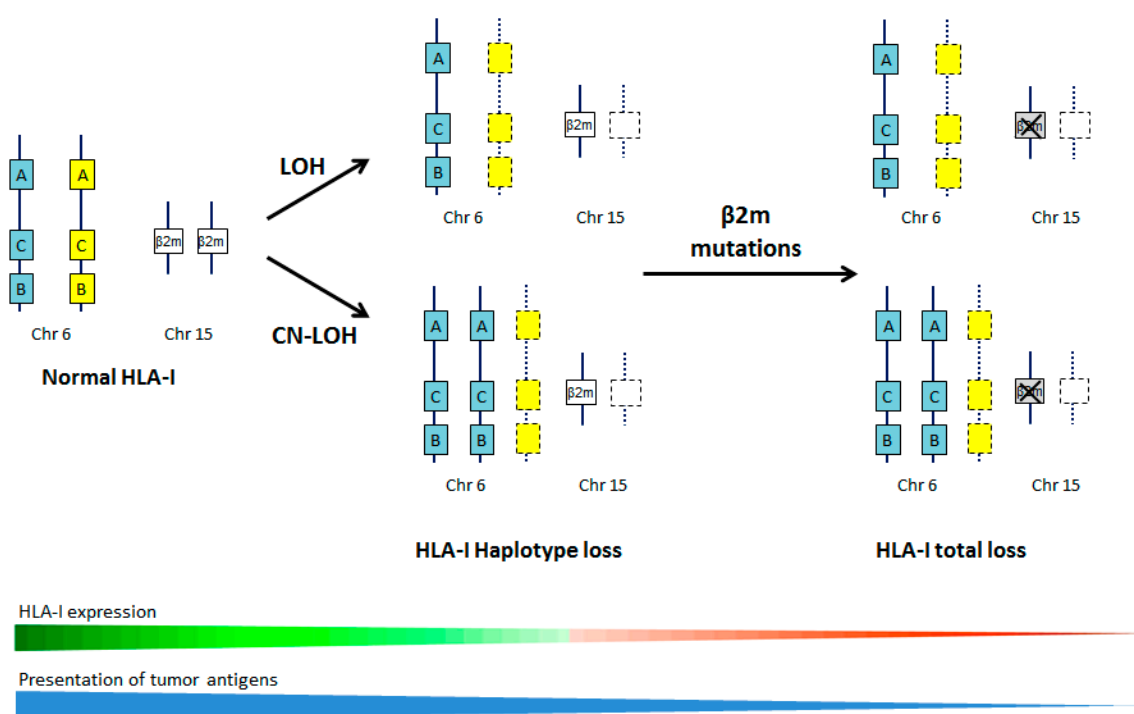

Figure 4. Schematic illustration of the accumulation of genetic alterations in chromosomes 6 and 15 (LOH, CN-LOH and $\beta 2$-microglobuline mutations) accompanied by the decrease in tumor HLA-I expression and antigen presentation during the natural history of tumor development.

As we mentioned earlier, $\mathrm{LOH}$ is caused by a variety of genetic mechanisms. Our study shows that the most frequent mechanism is CN-LOH-6 (6pterqter) and CN-LOH-15 (15q11.2qter). In a recent publication, it was demonstrated that a whole-genome doubling (WDG) involving the duplication of a complete set of chromosomes, is a common feature in carcinogenesis [41]. WGD has been linked to increased tumor cell diversity, accelerated cancer genome evolution and worse prognosis $[1,3,4,41]$. In this sense, many observations suggest that LOH-6 and LOH-15 may be a far more prevalent form of immune evasion. Given the frequency of $\mathrm{LOH}$ detected in various types of untreated tumors, it may be important to analyze LOH- 6 and -15 when designing patient-specific immunotherapy approaches. Importantly, this type of $H L A$ alteration can be undetected and unnoticed in tumor cell or tissue with $H L A-I / \beta 2 M$ positive surface expression. In Figure 4, we illustrate this progressive accumulation of $\mathrm{LOH}$ and mutations in $H L A$ genes during natural cancer evolution. In our study, we found an increased incidence of CN-LOH involving HLA genes across different tumor cell types, highlighting the importance of accurate $\mathrm{LOH}$ detection as a pan-cancer biomarker. 


\section{Conclusions}

$\mathrm{LOH}$ in the HLA locus is increasingly being recognized as an early and important mechanism of immune escape as well as a proposed biomarker for immunotherapy response. Neoantigens that bind to a deleted HLA allele will no longer be presented to the immune system, potentially allowing subclones with these deletions to escape immune surveillance. In this work, using SNP array analysis, we demonstrated that LOH-6 and -15 represent a common chromosomal alteration in tumor cells and tumor tissues of distinct histological type that are homozygous for HLA or show a selective loss of HLA expression. The incidence of LOH-6 was much higher than of LOH-15. Importantly, the most frequently observed pattern was CN-LOH-6 involving the whole chromosome 6 and duplication of the other one. Analysis of LOH in HLA genes may have important implications for the understanding a clonal evolution of tumors, for predicting response to immunotherapy and for the design of more efficient neoantigen-based therapeutic vaccines.

Author Contributions: M.A.G., F.P. and T.R.—sample selection, immunohistochemistry, SNP analysis and data interpretation; F.P. also performed tumor microdissection, DNA extraction and SNP assay; J.R.V.-SNP data analysis and interpretation; F.G., P.A. and M.A.G.-data analysis and manuscript preparation; F.G., N.A. and F.R.-C. designed and coordinated the study and drafted the manuscript. All authors have read and agreed to the published version of the manuscript.

Funding: This work was supported by grants from the ISCIII Research Institute co-financed by the European Union and Ministerio de Ciencia e Innovación (FEDER-Fondo Europeo de Desarrollo Regional and National Plan 2020, MICIN) (PI17/00197, PI18/00826, and PID2020-115087GB-100), and by the Junta de Andalucía in Spain (Group CTS-143 and B-CTS-410-UGR-20). P.A is supported by the Consejería de Salud, Junta de Andalucía through the contract “Nicolás Monardes" [C-0013-2018].

Institutional Review Board Statement: The study was conducted according to the guidelines of the Declaration of Helsinki, and approved by the Ethics Committee of the Virgen de las Nieves University Hospital and ibsGranada (PI17/00197).

Informed Consent Statement: Informed consent was obtained from all subjects involved in the study.

Data Availability Statement: The data presented in this study is contained within the article and are available on request from the corresponding author.

Acknowledgments: The authors would like to thank Mónica Bernal for the critical review of the manuscript. The results of this work are part of the doctoral thesis of Maria Antonia Garrido as a part of the Doctoral Program in Biomedicine at the University of Granada.

Conflicts of Interest: The authors declare no conflict of interest.

\section{References}

1. Garrido, F.; Cabrera, T.; Concha, A.; Glew, S.; Ruiz-Cabello, F.; Stern, P.L. Natural history of HLA expression during tumour development. Immunol. Today 1993, 14, 491-499. [CrossRef]

2. Browning, M.; Petronzelli, F.; Bicknell, D.; Krausa, P.; Rowan, A.; Tonks, S.; Murray, N.; Bodmer, J.; Bodmer, W. Mechanisms of loss of HLA class I expression on colorectal tumor cells. Tissue Antigens 1996, 47, 364-371. [CrossRef]

3. Koopman, L.A.; Corver, W.E.; van der Slik, A.R.; Giphart, M.J.; Fleuren, G.J. Multiple genetic alterations cause frequent and heterogeneous human histocompatibility leukocyte antigen class I loss in cervical cancer. J. Exp. Med. 2000, 191, 961-976. [CrossRef]

4. Romero, J.M.; Jimenez, P.; Cabrera, T.; Cozar, J.M.; Pedrinaci, S.; Tallada, M.; Garrido, F.; Ruiz-Cabello, F. Coordinated downregulation of the antigen presentation machinery and HLA class I/beta2-microglobulin complex is responsible for HLA-ABC loss in bladder cancer. Int. J. Cancer 2005, 113, 605-610. [CrossRef] [PubMed]

5. Jimenez, P.; Canton, J.; Collado, A.; Cabrera, T.; Serrano, A.; Real, L.M.; Garcia, A.; Ruiz-Cabello, F.; Garrido, F. Chromosome loss is the most frequent mechanism contributing to HLA haplotype loss in human tumors. Int. J. Cancer 1999, 83, 91-97. [CrossRef]

6. Serrano, A.; Tanzarella, S.; Lionello, I.; Mendez, R.; Traversari, C.; Ruiz-Cabello, F.; Garrido, F. Rexpression of HLA class I antigens and restoration of antigen-specific CTL response in melanoma cells following 5-aza-2'-deoxycytidine treatment. Int. J. Cancer 2001, 94, 243-251. [CrossRef] [PubMed]

7. Torres, M.J.; Ruiz-Cabello, F.; Skoudy, A.; Berrozpe, G.; Jimenez, P.; Serrano, A.; Real, F.X.; Garrido, F. Loss of an HLA haplotype in pancreas cancer tissue and its corresponding tumor derived cell line. Tissue Antigens 1996, 47, 372-381. [CrossRef] [PubMed] 
8. Maleno, I.; Cabrera, C.M.; Cabrera, T.; Paco, L.; Lopez-Nevot, M.A.; Collado, A.; Ferron, A.; Garrido, F. Distribution of HLA class I altered phenotypes in colorectal carcinomas: High frequency of HLA haplotype loss associated with loss of heterozygosity in chromosome region 6p21. Immunogenetics 2004, 56, 244-253. [CrossRef] [PubMed]

9. Maleno, I.; Romero, J.M.; Cabrera, T.; Paco, L.; Aptsiauri, N.; Cozar, J.M.; Tallada, M.; Lopez-Nevot, M.A.; Garrido, F. LOH at 6p21.3 region and HLA class I altered phenotypes in bladder carcinomas. Immunogenetics 2006, 58, 503-510. [CrossRef] [PubMed]

10. Perea, F.; Sanchez-Palencia, A.; Gomez-Morales, M.; Bernal, M.; Concha, A.; Garcia, M.M.; Gonzalez-Ramirez, A.R.; Kerick, M.; Martin, J.; Garrido, F.; et al. HLA class I loss and PD-L1 expression in lung cancer: Impact on T-cell infiltration and immune escape. Oncotarget 2017, 9, 4120-4133. [CrossRef]

11. Paschen, A.; Mendez, R.M.; Jimenez, P.; Sucker, A.; Ruiz-Cabello, F.; Song, M.; Garrido, F.; Schadendorf, D. Complete loss of HLA class I antigen expression on melanoma cells: A result of successive mutational events. Int. J. Cancer 2003, 103, 759-767. [CrossRef] [PubMed]

12. Restifo, N.P.; Marincola, F.M.; Kawakami, Y.; Taubenberger, J.; Yannelli, J.R.; Rosenberg, S.A. Loss of functional beta 2microglobulin in metastatic melanomas from five patients receiving immunotherapy. J. Natl. Cancer Inst. 1996, 88, 100-108. [CrossRef]

13. Del Campo, A.B.; Kyte, J.A.; Carretero, J.; Zinchencko, S.; Mendez, R.; Gonzalez-Aseguinolaza, G.; Ruiz-Cabello, F.; Aamdal, S.; Gaudernack, G.; Garrido, F.; et al. Immune escape of cancer cells with beta2-microglobulin loss over the course of metastatic melanoma. Int. J. Cancer 2014, 134, 102-113. [CrossRef]

14. Garrido, F.; Cabrera, T.; Aptsiauri, N. "Hard" and "soft" lesions underlying the HLA class I alterations in cancer cells: Implications for immunotherapy. Int. J. Cancer 2010, 127, 249-256. [CrossRef]

15. Bernal, M.; Ruiz-Cabello, F.; Concha, A.; Paschen, A.; Garrido, F. Implication of the beta2-microglobulin gene in the generation of tumor escape phenotypes. Cancer Immunol. Immunother. 2012, 61, 1359-1371. [CrossRef]

16. Maleno, I.; Aptsiauri, N.; Cabrera, T.; Gallego, A.; Paschen, A.; Lopez-Nevot, M.A.; Garrido, F. Frequent loss of heterozygosity in the beta2-microglobulin region of chromosome 15 in primary human tumors. Immunogenetics 2011, 63, 65-71. [CrossRef]

17. Chowell, D.; Morris, L.G.T.; Grigg, C.M.; Weber, J.K.; Samstein, R.M.; Makarov, V.; Kuo, F.; Kendall, S.M.; Requena, D.; Riaz, N.; et al. Patient HLA class I genotype influences cancer response to checkpoint blockade immunotherapy. Science 2018, 359, 582-587. [CrossRef]

18. Carretero, R.; Cabrera, T.; Gil, H.; Saenz-Lopez, P.; Maleno, I.; Aptsiauri, N.; Cozar, J.M.; Garrido, F. Bacillus Calmette-Guerin immunotherapy of bladder cancer induces selection of human leukocyte antigen class I-deficient tumor cells. Int. J. Cancer 2011, 129, 839-846. [CrossRef]

19. Zaretsky, J.M.; Garcia-Diaz, A.; Shin, D.S.; Escuin-Ordinas, H.; Hugo, W.; Hu-Lieskovan, S.; Torrejon, D.Y.; Abril-Rodriguez, G.; Sandoval, S.; Barthly, L.; et al. Mutations Associated with Acquired Resistance to PD-1 Blockade in Melanoma. N. Engl. J. Med. 2016, 375, 819-829. [CrossRef] [PubMed]

20. Gettinger, S.; Choi, J.; Hastings, K.; Truini, A.; Datar, I.; Sowell, R.; Wurtz, A.; Dong, W.; Cai, G.; Melnick, M.A.; et al. Impaired HLA Class I Antigen Processing and Presentation as a Mechanism of Acquired Resistance to Immune Checkpoint Inhibitors in Lung Cancer. Cancer Discov. 2017, 7, 1420-1435. [CrossRef] [PubMed]

21. Sade-Feldman, M.; Jiao, Y.J.; Chen, J.H.; Rooney, M.S.; Barzily-Rokni, M.; Eliane, J.P.; Bjorgaard, S.L.; Hammond, M.R.; Vitzthum, H.; Blackmon, S.M.; et al. Resistance to checkpoint blockade therapy through inactivation of antigen presentation. Nat. Commun. 2017, 8, 1136. [CrossRef]

22. Montesion, M.; Murugesan, K.; Jin, D.X.; Sharaf, R.; Sanchez, N.; Guria, A.; Minker, M.; Li, G.; Fisher, V.; Sokol, E.S.; et al. Somatic HLA Class I Loss Is a Widespread Mechanism of Immune Evasion Which Refines the Use of Tumor Mutational Burden as a Biomarker of Checkpoint Inhibitor Response. Cancer Discov. 2021, 11, 282-292. [CrossRef]

23. Luo, G.; Santoro, I.M.; McDaniel, L.D.; Nishijima, I.; Mills, M.; Youssoufian, H.; Vogel, H.; Schultz, R.A.; Bradley, A. Cancer predisposition caused by elevated mitotic recombination in Bloom mice. Nat. Genet. 2000, 26, 424-429. [CrossRef] [PubMed]

24. Kumar, Y.; Yang, J.; Hu, T.; Chen, L.; Xu, Z.; Xu, L.; Hu, X.X.; Tang, G.; Wang, J.M.; Li, Y.; et al. Massive interstitial copy-neutral loss-of-heterozygosity as evidence for cancer being a disease of the DNA-damage response. BMC Med. Genom. $2015,8,42$. [CrossRef]

25. Thiagalingam, S.; Laken, S.; Willson, J.K.; Markowitz, S.D.; Kinzler, K.W.; Vogelstein, B.; Lengauer, C. Mechanisms underlying losses of heterozygosity in human colorectal cancers. Proc. Natl. Acad. Sci. USA 2001, 98, 2698-2702. [CrossRef] [PubMed]

26. Rodriguez, T.; Mendez, R.; Roberts, C.H.; Ruiz-Cabello, F.; Dodi, I.A.; Lopez Nevot, M.A.; Paco, L.; Maleno, I.; Marsh, S.G.; Pawelec, G.; et al. High frequency of homozygosity of the HLA region in melanoma cell lines reveals a pattern compatible with extensive loss of heterozygosity. Cancer Immunol. Immunother. 2005, 54, 141-148. [CrossRef]

27. Mendez, R.; Rodriguez, T.; Del Campo, A.; Monge, E.; Maleno, I.; Aptsiauri, N.; Jimenez, P.; Pedrinaci, S.; Pawelec, G.; Ruiz-Cabello, F.; et al. Characterization of HLA class I altered phenotypes in a panel of human melanoma cell lines. Cancer Immunol. Immunother. 2008, 57, 719-729. [CrossRef] [PubMed]

28. Montes, P.; Kerick, M.; Bernal, M.; Hernandez, F.; Jimenez, P.; Garrido, P.; Marquez, A.; Jurado, M.; Martin, J.; Garrido, F.; et al. Genomic loss of HLA alleles may affect the clinical outcome in low-risk myelodysplastic syndrome patients. Oncotarget 2018, 9 , 36929-36944. [CrossRef] [PubMed] 
29. Lozano, F.; Santos-Aguado, J.; Borche, L.; Places, L.; Domenech, N.; Gaya, A.; Vilella, R.; Vives, J. Identification of the amino acid residues defining an intralocus determinant in the alpha 1 domain of HLA-A molecules. Immunogenetics 1989, 30, 50-53. [CrossRef]

30. Lozano, F.; Borche, L.; Places, L.; Alberola-Ila, J.; Gaya, A.; Vilella, R.; Vives, J. Biochemical and serological characterization of a public antigenic determinant present on HLA-B molecules. Tissue Antigens 1990, 35, 193-195. [CrossRef]

31. Doherty, P.C.; Zinkernagel, R.M. Enhanced immunological surveillance in mice heterozygous at the H-2 gene complex. Nature 1975, 256, 50-52. [CrossRef]

32. Garrido, F.; Ruiz-Cabello, F.; Cabrera, T.; Perez-Villar, J.J.; Lopez-Botet, M.; Duggan-Keen, M.; Stern, P.L. Implications for immunosurveillance of altered HLA class I phenotypes in human tumours. Immunol. Today 1997, 18, 89-95. [CrossRef]

33. McGranahan, N.; Rosenthal, R.; Hiley, C.T.; Rowan, A.J.; Watkins, T.B.K.; Wilson, G.A.; Birkbak, N.J.; Veeriah, S.; Van Loo, P.; Herrero, J.; et al. Allele-Specific HLA Loss and Immune Escape in Lung Cancer Evolution. Cell 2017, 171, 1259-1271.e11. [CrossRef]

34. Yeung, J.T.; Hamilton, R.L.; Ohnishi, K.; Ikeura, M.; Potter, D.M.; Nikiforova, M.N.; Ferrone, S.; Jakacki, R.I.; Pollack, I.F.; Okada, H. $\mathrm{LOH}$ in the HLA class I region at 6p21 is associated with shorter survival in newly diagnosed adult glioblastoma. Clin. Cancer Res. 2013, 19, 1816-1826. [CrossRef] [PubMed]

35. Harima, Y.; Harima, K.; Sawada, S.; Tanaka, Y.; Arita, S.; Ohnishi, T. Loss of heterozygosity on chromosome 6p21.2 as a potential marker for recurrence after radiotherapy of human cervical cancer. Clin. Cancer Res. 2000, 6, 1079-1085. [PubMed]

36. Facoetti, A.; Nano, R.; Zelini, P.; Morbini, P.; Benericetti, E.; Ceroni, M.; Campoli, M.; Ferrone, S. Human leukocyte antigen and antigen processing machinery component defects in astrocytic tumors. Clin. Cancer Res. 2005, 11, 8304-8311. [CrossRef]

37. Chen, H.; Carrot-Zhang, J.; Zhao, Y.; Hu, H.; Freeman, S.S.; Yu, S.; Ha, G.; Taylor, A.M.; Berger, A.C.; Westlake, L.; et al. Genomic and immune profiling of pre-invasive lung adenocarcinoma. Nat. Commun. 2019, 10, 5472. [CrossRef] [PubMed]

38. Iorgulescu, J.B.; Braun, D.; Oliveira, G.; Keskin, D.B.; Wu, C.J. Acquired mechanisms of immune escape in cancer following immunotherapy. Genome Med. 2018, 10, 87. [CrossRef] [PubMed]

39. Carretero, R.; Romero, J.M.; Ruiz-Cabello, F.; Maleno, I.; Rodriguez, F.; Camacho, F.M.; Real, L.M.; Garrido, F.; Cabrera, T. Analysis of HLA class I expression in progressing and regressing metastatic melanoma lesions after immunotherapy. Immunogenetics 2008, 60, 439-447. [CrossRef]

40. Mendez, R.; Ruiz-Cabello, F.; Rodriguez, T.; Del Campo, A.; Paschen, A.; Schadendorf, D.; Garrido, F. Identification of different tumor escape mechanisms in several metastases from a melanoma patient undergoing immunotherapy. Cancer Immunol. Immunother. 2007, 56, 88-94. [CrossRef]

41. Lopez, S.; Lim, E.L.; Horswell, S.; Haase, K.; Huebner, A.; Dietzen, M.; Mourikis, T.P.; Watkins, T.B.K.; Rowan, A.; Dewhurst, S.M.; et al. Interplay between whole-genome doubling and the accumulation of deleterious alterations in cancer evolution. Nat. Genet. 2020, 52, 283-293. [CrossRef] [PubMed] 